\title{
Outra contribuição à ideia de projeto e representação em arquitetura
}

José Barki

Doutor pela PROURB-FAU-UFRJ, Mestre pela Cornell University, Professor Associado III - PROURB-FAU-UFRJ.

Contato: zbki@globo.com

James Miyamoto

Doutor pela PROURB-FAU-UFRJ, Mestre pela Nagoya University, Professor Associado II - PROURB-FAU-UFRJ.

Contato: jamesmiya@terra.com.br

\section{Rodrigo Paraizo}

Doutor pela PROURB-FAU-UFRJ, Mestre pela PROURB-FAU-UFRJ, Professor Adjunto IV - PROURB-FAU-UFRJ.

Contato: rparaizo@gmail.com

\section{RESUMO}

$\mathrm{O}$ artigo constitui um ensaio para analisar formas de representação em arquitetura e urbanismo. O ponto de partida são as transformaçôes do próprio ato de representar, em especial por meio do desenho, trazidas pelas mídias digitais, e a discussão sobre a relação intrínseca entre o ato de projetar e a representação. A partir da discussão sobre modos de classificação do desenho de arquitetura propostos por alguns autores consagrados, o artigo propôe o agrupamento quanto aos modos de ação propostos: análise, argumentação e construção. Finalmente, estabelece a relação de complementaridade e simultaneidade entre esses modos, além de sua pertinência para abranger modos de produção digital contemporâneos.

Palavras-chave: Representação Arquitetônica; Retórica Visual; Concepção de Projeto; Análise Gráfica

\begin{abstract}
This paper is an essay analysing forms of representation in architecture and urbanism. It starts by pointing out the transformations to the practice of representation, particularly drawings, brought by digital media, and discussing the intrinsic relationship between the act of design and representation. Departing from architecture drawing classifications proposed by authors, we propose another one based on the intended modes of action codified in the drawings: analysis, argumentation and construction. The paper concludes establishing relationships of complementarity and simultaneity among the different modes, and highlighting their pertinence to encompass digital modes of architectural production.
\end{abstract}

Key-words: Architectual Representation; Visual Rhetoric; Design Creation; Graphic Analysis 


\section{Introdução}

A proposta deste artigo é debater a questão da 'projetação' em arquitetura, mais especificamente do modo de projetar através do desenho, ou da materialização visual das ideias arquitetônicas. Realmente, uma vez mais, debruça-se sobre a já longa historiografia da arquitetura para abordagem desse tema: "Um aspecto interessante da atividade de projeto é justamente a quantidade de teorias, metodologias, manuais de procedimentos e técnicas as mais diversas da qual foi objeto historicamente" (BISELLI, 2011).

A discussão do vínculo entre projeto e representação também estaria longe de ser inédita. Entretanto, novas formas de instrumentalização da ideia de representação, em suas fases principais de projeto: análise, concepção e projeto final, em um universo que se apropria cada vez mais dos recursos computacionais, merecem um olhar particular. Esse olhar sobre distintas intenções do desenho em arquitetura tem grande interesse para o que se possa explorar de modo consciente a contínua (e acelerada) transformação dessa prática, identificando mais claramente as especificidades de cada meio de produçáo gráfica no que diz respeito ao ato de projetar.

De acordo com Allen (2009), a arquitetura carrega uma contradição no que diz respeito às outras artes; por um lado, é alográfica, ou seja, dependente de notaçóes para ser executada (e isso pode ser feito à distância do autor), como a música; por outro, deixa efeitos duradouros no mundo, um objeto físico que se desprende dos seus executantes (e de seu autor) para ter uma presença muito mais perene, como a pintura ou a escultura. Ou ainda: "como pensar em um sistema que é ao mesmo tempo altamente abstrato e autorreferente, e ao mesmo tempo tem como objetivo transformaçôes instrumentais da realidade existente?" (ALLEN, 2009, p. 46; tradução nossa) É da natureza da representação em arquitetura, portanto, ser notacional, ainda que suas peças possam ser claramente pictóricas na aparência, e que venham a ser investidas de alto valor estético.
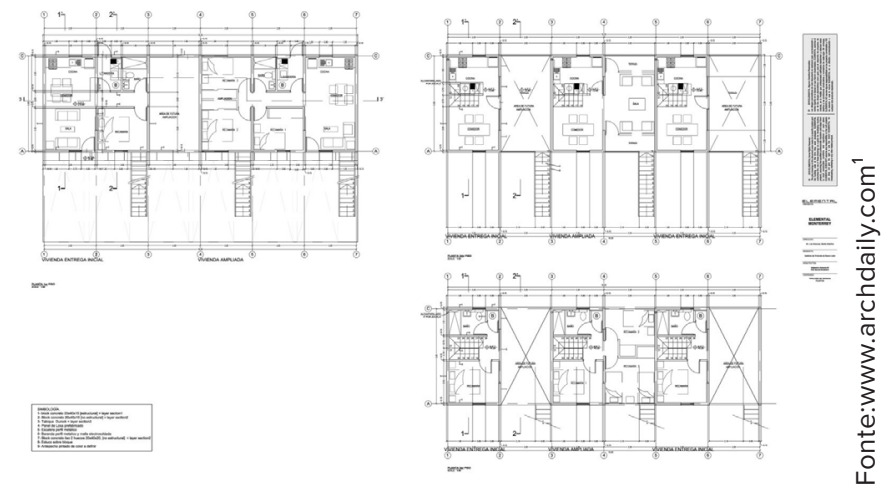

Figura 1: Planta do primeiro pavimento do projeto Monterrey, do escritório Elemental.

Entende-se que "uma representação não é a 'realidade em si', não pode ser o 'objeto em si' e será sempre menos do que aquilo a que se refere" (BARKI, 2003, p. 3). Isso ocorre porque a 'representaçâa' talvez não ambicione extrapolar certo nível de materialidade, em sua anima "consciente". Normalmente, se intui que os croquis, plantas, cortes, vistas e perspectivas intencionem se transformar em casas, edifícios ou parques - ainda que, possivelmente, a completude gráfica da representação se baste em si mesma.

De acordo com Sainz (2005, p.29),

não podemos afirmar que o desenho de arquitetura seja uma linguagem, mas o que podemos constatar é que o estudando como uma linguagem é possível descobrir sua estrutura específica, os elementos que a compóem e as relaçôes 
que se estabelecem entre eles (grifos no original; tradução nossa).

Do mesmo modo, o projeto pode ser entendido como o discurso do projetista, ou antes o seu modo preferencial de raciocinar e da mesma maneira que o vocabulário condiciona ou induz ao pensamento, os modos de projetar são indutores mais ou menos ativos daquilo que pode ser projetado. Mesmo a visão romântica seja do Taliesin, seja da construção favelada/vernácula - a experiência construtiva como estímulo ao aprendizado da ação projetual —, se encontra, nos dias de hoje, profundamente impregnada pelas questóes da representação gráfica e do desenho, em especial graças às linguagens de programação visual (das quais o plug-in Grasshopper talvez seja o representante mais conhecido), que ajudaram a popularizar algoritmos, lógica de programação e o próprio espírito de prototipagem e hacking entre os arquitetos. $\mathrm{Na}$ realidade, não se trata de uma questão competitiva entre instrumentos de ordens e objetivos distintos, como em estratégias mercadológicas contemporâneas de obsolescência programada. Considerar assim, contraporia, por exemplo, os croquis essencialmente "manuais" (sketches) à realidade virtual "eletrônica", quando, em realidade, cada prática envolve situaçóes diferentes.

Há, portanto, dois campos íntimos que se deparam, atualmente, com novos contornos das ideias de concepção, desenvolvimento e representação. Recentes instrumentos da 'projetaçáo' virtual, no emergente mundo da tecnologia da informação e comunicação, lançam mão do conceito de algoritmos, parametrização e a integração dos processos de produção e interdisciplinaridade. Do ponto de vista do Building Information Modeling (BIM), por exemplo, importa menos a codificação gráfica correta do que a correçáo dos atributos da entidade geométrica criada, que será responsável pela interligação apropriada da mesma com o resto do banco de dados. Em certo sentido, poderíamos dizer que está sempre acabado, ou seja, no máximo nível de detalhe. Apesar disso, ou por causa disso, vários pacotes de software já incluem "modos de esboço", por exemplo, que permitem o pensamento mais livre nos estágios iniciais, para o posterior refinamento e detalhamento da soluçáo. No que diz respeito à arquitetura de base algorítmica, por outro lado, é possível reconhecer nas progressivas iterações das funçôes e fórmulas elaboradas, paralelos com o processo tradicional de projetação, que inclui em esboços iniciais desenhados e diagramas ao longo do processo para visualizar soluçôes. Desse modo, se torna útil voltar mais uma vez às questôes de desenho associadas ao projeto, não para enquadrar $a$ priori as novas formas de projetaçáo em moldes antigos, mas para refletir sobre a essência desses moldes e conseguir perceber quais elementos realmente novos são introduzidos e quais devem ser simplesmente recuperados e reestruturados para suas novas encarnaçóes. Que rumos se vislumbram diante dos avanços contínuos desses sistemas? De que forma os espaços são, ou serão, concebidos? Que domínio o arquiteto exercerá sobre o projeto e suas naturais implicaçóes (construção, cultura, estrutura, lugar, materiais, programa etc.)?

\section{Projeto e Representaçáo}

Talvez o raciocínio imediato seja, 'em si', uma coisa simples: resolver problemas elementares de causa e efeito, proporçôes, identidade e diferença, entre outros. No entanto, os atos do pensamento humano abrangem um domínio incomparavelmente mais vasto, não só no espaço e no tempo, mas em graus de 'abstração' que vão além do espaço e do tempo. $\mathrm{O}$ universo do nosso raciocínio imediato é restrito 
em comparação com o de nossa percepção e fantasia. É a imaginação humana que produz as formas e as analogias que irão transcender infinitamente uma situação presente.

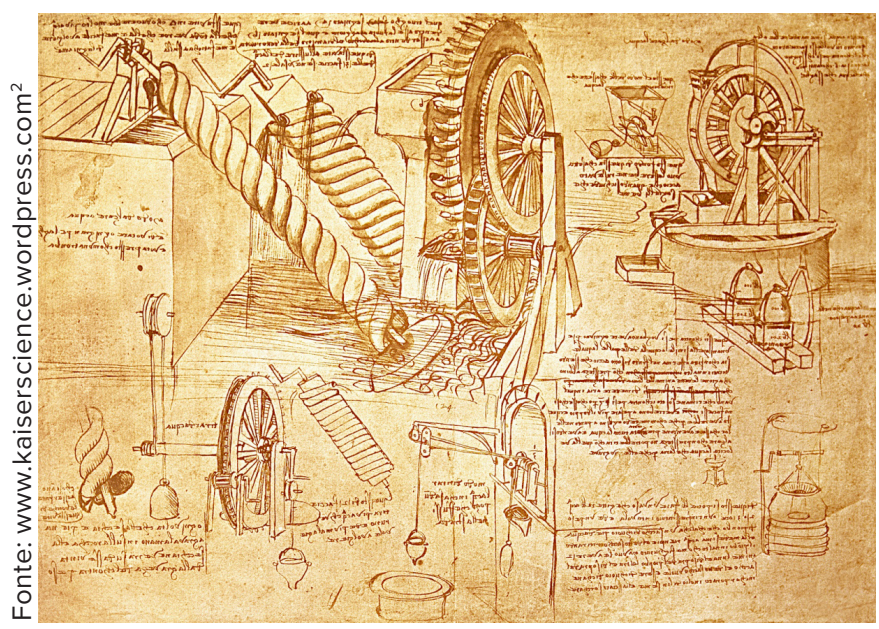

Figura 2: Croquis de Leonardo da Vinci.

A espécie humana tem feito, ao longo do tempo, um gigantesco esforço para aprimorar o raciocínio imediato por meio de artifícios: Os desenhos nas cavernas e o advento da linguagem articulada foram as primeiras modalidades de um 'pensamento artificial'. Logo em seguida, vieram a contagem e a invenção de narrativas que, preservadas, seriam passadas as geraçóes seguintes. Lendas e mitos desenvolveram culturas, fundaram as civilizações. $\mathrm{O}$ que nos torna humanos é o fato de sermos capazes de organizar como um conjunto aquilo que imaginamos, raciocinamos, memorizamos ou com o que nos emocionamos.

Entretanto, talvez o mais importante é que, com relação a este conjunto, somos também supostamente capazes de avaliar a veracidade ou falsidade daquilo que a nossa própria mente vai 'produzir' e 'conhecer'. Não podemos conhecer, pela observaçáo direta, e/ ou supostamente 'isenta', a imensidão do real. Mas podemos ter dela algum resultado que se traduz em imagens. É sobre estas imagens que se constrói um conhecimento dito racional. A razão humana parece não operar diretamente sobre os dados dos sentidos, mas sobre imagens depositadas na memória. A imaginação será a ponte entre o sensível e o inteligível: a imaginação é a mediadora.

Mesmo assim, para uma 'ação projetual' consequente, talvez se tenha que reconhecer no campo disciplinar da arquitetura três planos distintos, mas necessariamente relacionados: um plano básico em que se reconhecem os valores fundamentais da tradição ocidental de compromisso com a busca da verdade, ética, liberdade e democracia. Um outro plano que se poderia tratar como o mundo real no qual as coisas 'existem' e no qual, de fato, a arquitetura se realiza e se manifesta tanto como projeto (a ideia materialmente representada e apresentada) e/ou como espaço concretizado (construído). E um terceiro plano que se poderia tratar como formal/ideal. O plano de base estabelece um quadro de referência estável sem qualquer tipo de compromisso com o 'relativo': respeito absoluto com a coisa pública, com o esforço acumulado pelas geraçóes passadas para construir o bem comum e o legado para as geraçóes futuras. No plano das coisas reais os desafios que devem ser enfrentados hoje parecem se desdobrar em três questóes (temas) aparentemente simples, mas muito complexas: $1^{\circ}$ ) adequação ambiental; $2^{\circ}$ ) resposta/flexibilidade programática; $3^{\circ}$ ) processos físico-espaciais e construtivos. O último plano lidaria hipoteticamente com questôes fundamentais da forma/configuração arquitetônica, assumindo-se ser aceitável propor uma 'linguagem' elementar da arquitetura independente de tempo e lugar. Um modo de entendimento 'ideal', e por consequência inatingível, da autonomia da arquitetura - da arquitetura como uma função de nada mais do que a lógica da forma e do espaço. Em 
outras palavras, uma abordagem racionalista pura, absoluta e isenta - como se isso fosse possível; ou seja, assumir - como uma espécie de suspensão temporária da descrença - a ideia de que a 'razão' (talvez também o 'belo' e, quem sabe, o 'bom') da arquitetura é a arquitetura ela mesma. Este último plano abre algumas possibilidades propedêuticas interessantes, talvez por esse caminho se possa estimular uma introdução para o aprendizado do ofício e para a compreensão das suas dificuldades práticas.

\section{O desenho na arquitetura}

Pode-se iniciar a argumentação, ainda inspirado em Biselli, que:

O partido arquitetônico, (...) se dá no momento em que o texto, compreendido como articulação semântica - pensamento e ideia - expressa na linguagem verbal, se transforma em ícone, transposiçáo da linguagem verbal para a linguagem não verbal, ou de maneira mais precisa, a operação que faz o arquiteto é de texto e ícone para ícone, pois o programa é texto e o lugar é ícone. (BISELLI, 2011)

Do ponto de vista do processo em relação ao projeto de arquitetura e sua representação, parte-se de uma tentativa de se organizar seu desenvolvimento, através da introdução de alguns pressupostos gerais básicos. As tentativas de classificar os desenhos de arquitetura variam quanto aos termos e quantidade de tipos, mas dão indício de que não podem ser tratados todos da mesma forma, e que seus significados diferem o suficiente entre si para que sejam estudados com mais atenção. Herbert (1993, p.12), por exemplo, ao caracterizar os desenhos de estudo em sua obra, os diferencia dos desenhos de apresentação e de construção, em uma organização tripartite bastante recorrente. Saenz, em sua obra sobre o desenho de arquitetura (2005, p. 46), reconhece que um desenho só pode ser chamado de arquitetônico devido à finalidade, ou seja, por elementos que são, na verdade, extra-gráficos. Com isso, dá pistas de que a intençáo do desenho pode ser a chave para sua classificação e estudo. Em capítulo posterior, intitulado "Instrumental, Analítico e Expressivo" (e que, portanto, também remete à divisão tripartite), Saenz agrupa como finalidades do desenho arquitetônico "projetos", "vistas" (no sentido de simular aquilo que se vê), "modelos", "levantamentos", "ilustraçôes", "análises gráficas" e "fantasias expressivas".

Laseau, por sua vez, em seu livro "Graphic Thinking for Architects and Designers" (2000), oferece uma classificação de "habilidades aplicadas" ("applied skills", no original), correspondendo a "análise", "exploraçáo", "descoberta" e "verificação"; e outra para a "comunicaçáo", que se divide em "processo", "design individual", "design em equipe" e "design público". Com isso, foca primeiro nas questôes da criação e desenvolvimento das ideias e, posteriormente, no registro e transmissão das informaçôes.

A partir disso, reconhecemos algumas funçôes essenciais do desenho de projeto: o entendimento, ou elaboração, voltado para o projetista ou sua equipe próxima, quando a situação de projeto está sendo entendida e processada; a argumentação ou apresentação, em que a questão principal está relacionada ao convencimento de um público determinado; e a construção ou registro, em que o essencial é a documentação legal ou o conjunto de instruçôes para que determinada obra tenha sua construção assegurada independentemente da presença do projetista. $\mathrm{Na}$ turalmente, um desenho criado para atender a uma 
demanda pode ser (e, muitas vezes, é) — aproveitado em outro contexto, mas consideramos que as circunstâncias originais são de grande importância para as decisôes quanto a técnicas, modos de desenhar, tempo de desenho, entre outras.

Assim, oferece-se uma nomenclatura original, ainda que as significâncias possam ser antigas e universais. Assume-se que haja uma narrativa de projetação com as seguintes premissas instrumentais: a) "desenho e entendimento", b) "desenho e argumentação" e c) "desenho e construção". Novamente, não se espera que seja um processo linear em que haja uma estanqueidade ou independência plena de fases. Ao contrário, prevê-se que haja uma série de naturais avanços e retrocessos ao longo do percurso de materialização da concepção, desenvolvimento e representação do projeto de arquitetura. Um ponto central é entender se "os aplicativos disponíveis e as formas de uso do meio digital ainda não superaram os recursos de representação tradicionais" (BARKI, 2003, p.6) e identificar os rumos contemporâneos do sentido de 'projetaçáa'. Analisar cada uma dessas etapas, em suas especificidades, e enlevar o contexto, auxiliará a compreensão dos argumentos e conclusôes apresentadas.

Propóe-se, como acima exposto, três momentos que se interligam e norteiam a ideia de representação de projetos de arquitetura;

\section{a) Desenho e análise}

A fase de análise do problema lida com a questão principal do entendimento físico, espacial e cultural do lugar e com as demandas preliminares intrínsecas ao projeto. Diz-se que, em "arquitetura, há uma forte crença de que tudo já foi feito, em alguma extensão (...), e que a originalidade não repousa na descoberta de algo novo, mas na interpretação e apropriação de algo que já existe" (SIMITCH e WARKE, 2014, p. 9). Compreender a situação existente, embora seja uma ação de subjetividade infinita, pressupóe margens de manobra que devem acolher impulsos com orientaçôes que busquem um pragmatismo assertivo. A reunião de dados não deve consistir em um acúmulo desenfreado e acrítico de material.

Nesta fase, de entendimento da situação existente, o dado original em relação a projetos assistidos por computador, principalmente, em escalas territoriais, é a possibilidade de se desenvolver análises através da sobreposição de camadas de diferentes disciplinas sobre uma única base cartográfica.

Quando se trata da análise "pura", na qual não transparece a proposta de projeto, a arquitetura muitas vezes busca elementos gráficos e técnicas de campos mais afeitos aos estudos espaciais sem o método do projeto, em especial a geografia, a cartografia e a sociologia, por exemplo. Outros instrumentos importantes vinculam-se às estruturas de georreferenciamento, levantamentos planialtimétricos, escaneamento tridimensional de fachadas, simulação de situaçôes complexas, entre outros.

Vale dizer que o entendimento passa também pela elaboração da solução. Ou seja, a análise já pressupóe uma visão sobre o problema, de modo que não se trata de uma etapa à parte da criaçáo, mas uma leitura espacial investida das crenças e convicçôes do projetista. Essa visão vai sendo aos poucos depurada, face aos dados do problema, mas os próprios dados a serem coletados não estão definidos a priori; serão escolhidos de acordo com a visão de projeto subjacente. Em contrapartida, é preciso entender também o projeto como uma hipótese, um modo de pesquisa e estudo sobre o problema determinado pelo projetista. 


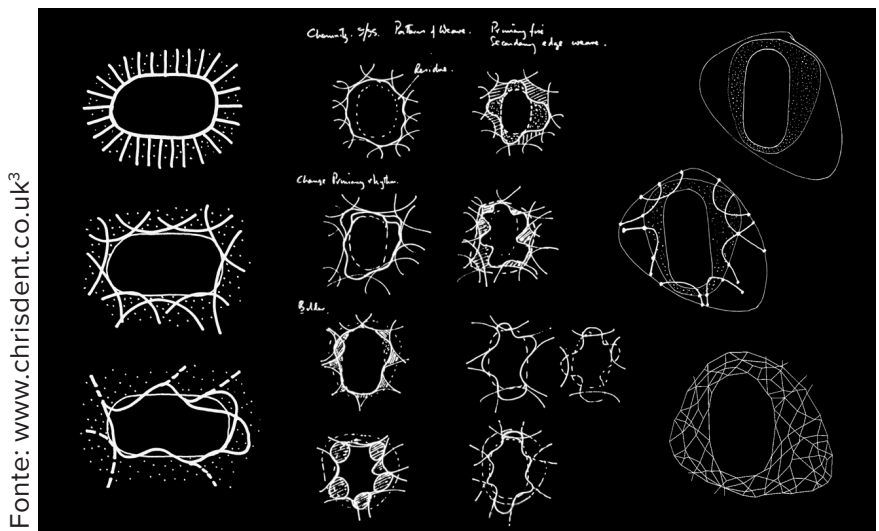

Figura 3: Croquis do Chemnitz Stadium, por Cecil Balmond.

O croqui de estudo, portanto, carrega em si as questôes escolhidas pelo projetista para serem enunciadas e, eventualmente, respondidas. Do mesmo modo, as técnicas computacionais de análise serão igualmente carregadas de convicçóes e indutoras dos caminhos a serem trilhados; e também as linhas de código dos algoritmos irão carregar não apenas o estilo de seus programadores, mas suas crenças a respeito do que efetivamente constitui o campo do problema.

Para os arquitetos, a concepção de projetos envolve as capacidades de abstraçáo (acerca de uma demanda ou dados de um programa de necessidades) e de antecipação (apresentação e representação de soluçóes plausíveis). É frequentemente tratada como um procedimento ordenado e metódico com uma estrutura 'linear' e 'cíclica' (ZEISEL, 1981; PROST,1992; JONES, 1992; CONAN, 1990; BROADBENT, 1973;ARCHER, 1968).

No entanto, como será possível abstrair ou antecipar sem imaginar? Por conta desta questáo alguns autores propóem que a concepçáo se dá como uma espécie de "conversação reflexiva com uma situação" e é com o 'desenho' que o arquiteto estimula uma modalidade de imaginação que Bachelard diria 'ativa': uma imaginação com 'vontade'.
Com efeito, o que intermedia os preceitos iniciais da concepção é a inclinação subjetiva do projetista, a partir da análise que precede a situação existente de demanda e, concomitantemente, de restriçóes intrínsecas. A forma interpretativa e a reação "argumentadora" que se materializa nos esboços iniciais de um projeto é o que caracteriza, afinal, a originalidade e inventividade do arquiteto.

Um dos recursos principais nesta fase de concepção de projeto, como precisamente conceituado por Barki, é a "notação gráfica" (esquemas, diagramas, esboços, croquis, etc.) que serve para instrumentalizar o arquiteto em seus pensamentos e propostas, em um processo do pensamento visual que integra percepção, imaginação e desenho. $\mathrm{O}$ croqui é o caminho mais corriqueiro e imediato utilizado pelos projetistas para análise de uma paisagem ou ainda para experimentar os primeiros riscos especulativos de uma edificação, por exemplo.

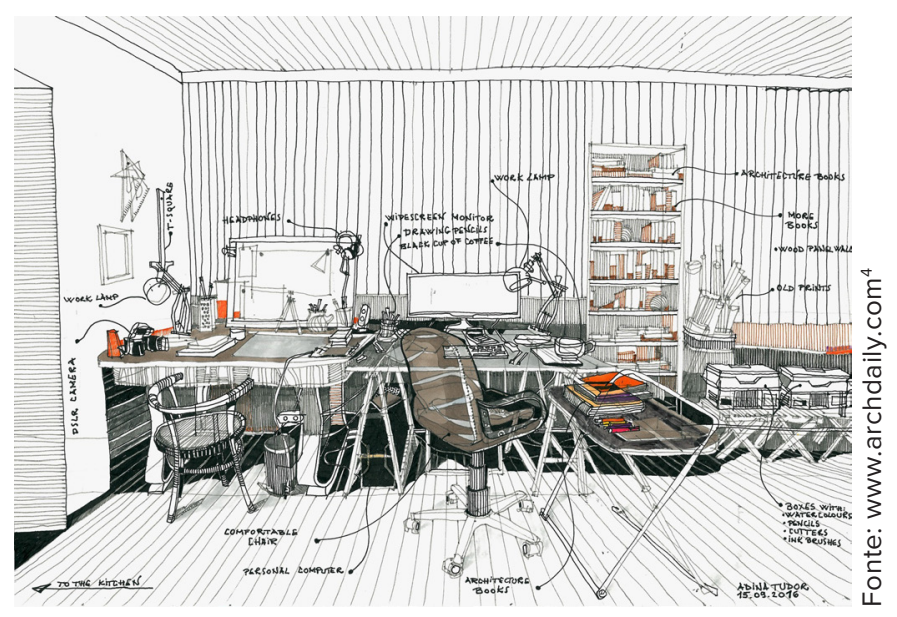

Figura 4: Espaço de trabalho, por Tudor Adina-Mihaela.

Recentemente, o processo de concepção de projeto tem sido desenvolvido, de forma corriqueira, a partir do escaneamento de modelos tridimensionais reais cujas montagens tem objetivo semelhante ao do 
tradicional croqui (desenho). Ou seja, especula-se quais feiçóes espaciais e formais deverão ser dadas ao objeto arquitetônico, com o uso de maquetes e, em momento subsequente, o material gráfico passa a ser desenvolvido.

\section{b) Desenho e argumentação}

O papel argumentativo do desenho no projeto de arquitetura se desenvolve em dois caminhos: no primeiro, se confunde com a análise, por sucessivas iterações e modificaçóes que vão criando uma espécie de diálogo interno exteriorizado do projetista.

O segundo modo, que é da argumentação propriamente dita, trata do convencimento de outros sobre a pertinência da "solução" - da validade e qualidade do projeto, portanto. Wang e Groat (2002, p. 84) chegam a sugerir que a capacidade de persuasão é mais importante que a de prediçáo, naquilo que se refere às teorias de projeto. Dado que a natureza dos problemas de projeto, segundo Rowe (1998, p. 41), é tal que a própria definição do problema afeta o tipo de soluçáo desenvolvida, e nem estâo bem definidos os pontos de avaliação ou de completude; ademais, tanto quanto subjetividade, eles envolvem escolhas e juízos políticos, que irão dar estabelecer a hierarquia desejada dos valores.

Pela retórica, portanto, é possível identificar valores e juízos envolvidos nas proposiçóes de projeto, e encontrar uma ressonância que pode tanto ser localizada quanto um reflexo de questóes culturais mais perenes. A retórica, a arte do discurso, estuda as técnicas para motivar, persuadir ou informar os interlocutores. Hill e Hemers (2008) propóem o conceito da "retórica visual", ou seja, da capacidade de persuasão das imagens; e podemos notar os três diferentes tipos de prova retórica presentes na argumentação arquitetônica em geral, e nas suas peças gráficas em particular: ethos (a credibilidade do enunciador), pathos (o apelo às emoçóes da plateia pelas figuras de retórica) e logos (os raciocínios ou enunciaçóes lógicas). Blair (2008) sustenta a possibilidade de uma "argumentação visual", que seria a própria sustentação da retórica visual, já que as imagens podem apresentar proposiçóes capazes de convencimento racional (ain$\mathrm{da}$ que com apelo às emoçóes) do interlocutor. De fato, as imagens teriam apelo retórico ainda mais potente que as palavras, ao acessar as emoçóes diretamente e particularizar exemplos e argumentos. Uma representação, afinal, é menos que realidade, envolvendo uma redução operativa por meio da seleção, e mais do que a realidade, ao realizar uma adição interpretativa da intenção de seu autor (LASEAU, 2005).

Podemos notar, no discurso arquitetônico atual, algumas tendências, cada uma delas trazendo valores específicos: a imersão buscada pelas renderizaçôes foto-realistas, produzidas com cada vez mais rapidez, acabou levando a uma valorização da construção consciente da imagem, seja através da colagem (em geral digital), seja através das técnicas ostensivamente manuais, com algum destaque para o desenho manual e a aquarela, por exemplo, buscando trazer a mão do autor para a apresentação da obra.

Por outro lado, as funçóes geradoras de geometria compóem parte da argumentação que recorre à técnica, do mesmo modo que a utilização de infográficos variados. Destes, os diagramas são um caso à parte, ao mesmo tempo gesto sensível e razão, comprimindo os fatores essenciais da racionalidade do projeto ao mesmo tempo que, como síntese, exibe a subjetividade necessária para sua compreensão. 


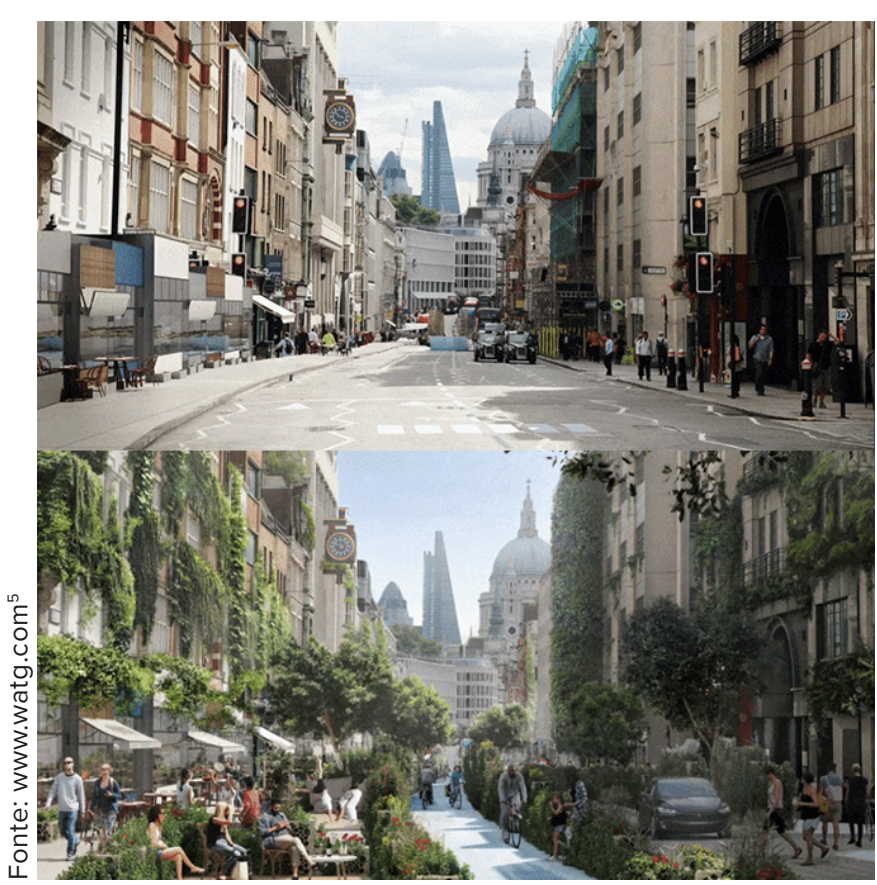

Figura 5: CouldFleet Street, Londres, quadros de imagem GIF animada.

\section{c) Desenho e construção}

A gênese do ofício de projetar é indissociável da ideia de construir. A concepção arquitetônica evoluída precede a obra construída. "No desenvolvimento da concepção, o arquiteto passa a desenvolver um especial interesse por padrôes, modulação, ordenação, regularidade e equilíbrio. Busca princípios elementares que definam uma lógica que facilite a concepção arquitetônica. A unidade formal e a solução plástica da obra são entâo resolvidas por estes princípios." (BARKI et. al., 2008)

Hoje vivemos num mundo imerso em uma quantidade avassaladora de imagens que são consumidas com uma velocidade e voracidade espantosa. Esta situação, paradoxalmente, parece que gradativamente esmaga a nossa capacidade de imaginar com autonomia. Contudo, recoloca-se o tema do "projeto assistido por computador" em outra perspectiva.

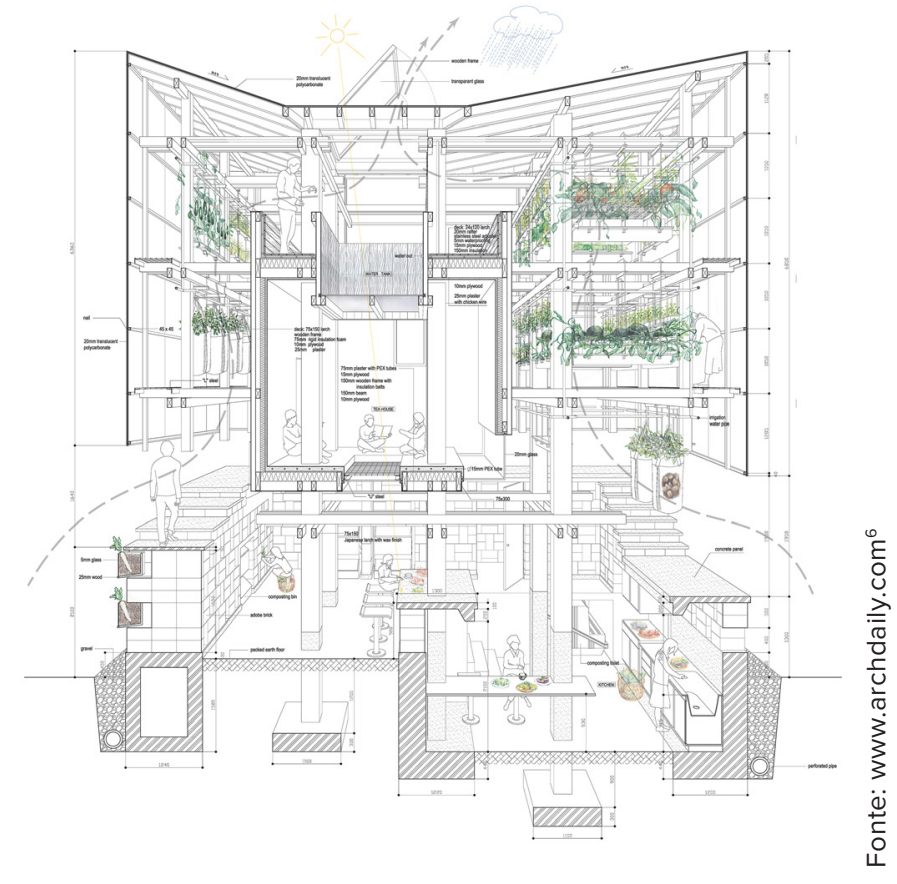

Figura 6: Nest We Grow / College Environmental / UC Berkely / KengoGuma\& Associates.

Por outro lado, a arquitetura algorítmica, associada à fabricação digital, ao explorar não apenas as formas complexas, mas as maneiras de produzí-las, seja como maquete, seja como formas construídas, resgata o fazer para a linha de frente do pensamento de projeto. Ao construir uma definição de Grasshopper, no Rhino, (não por acaso uma linguagem de programação visual, em que as relaçôes entre as diversas funções são construídas graficamente), o projetista está ao mesmo tempo interpondo um passo a mais a fórmula - entre o gesto e a forma e trazendo para o momento da criação os fatores construtivos.

De um modo ou de outro, a chamada "arquitetura sem papel”, que engloba tanto o uso dos arquivos digitais como documentos legais, quanto a produçáo de peças diretamente do computador, sem desenhos executivos - quando muito, manuais de montagem (que podem ser interpretados como o detalhamento 
executivo em sua essência), não implica a inexistência do desenho de construção, mas na sua sofisticação em termos de precisão e complexidade. Por outro lado, acarreta também questôes sérias de preservação digital e posterior recuperação dos dados para pesquisa histórica, como a necessidade de compatibilidade reversa e o estabelecimento de políticas de versóes - ajudando a determinar quais arquivos são válidos para entender a obra construída e quais são pontos importantes do processo de projeto, um caso particular da compressáo entre a criação e a construção em que, ao se confundirem, tendem a obscurecer a posterior visualização do desenvolvimento da ideia projetual.

\section{Breve análise comparativa}

Essas três intençóes, ou momentos, da representação do projeto, estão longe de constituírem etapas distintas e ordenadas de uma dita evolução de um projeto, mas representam diferentes pontos de vista adotados durante o processo de amadurecimento de uma ideia projetual. Cada um desses olhares de representação traz tratamentos distintos para determinadas qualidades gráfico-projetuais. Tomemos o rigor como exemplo dessas categorias: é na construção que se torna normalmente mais vital e é mais comum que a análise e a argumentação possam trabalhar com tolerâncias maiores, ainda que muitas vezes precisem de grande clareza e objetividade na conjugação de determinadas partes, ou mesmo na definição de determinados conceitos.

A questão da escala também pode ser analisada sob esse prisma, levando a observaçóes interessantes. Ainda que a narrativa tradicional do projeto seja "do geral para o particular", e que as ideias tendem a se esboçar seguindo esse modelo, não é possível afirmar que análise, argumentação e construção constituam necessariamente uma aproximação sucessiva do detalhe. Análises locais ou de detalhes podem ter grandes efeitos na situação geral - e assim serem apresentados como argumentos; do mesmo modo que os autômatos celulares em arquitetura generativa desenvolvem uma forma geral de "de baixo para cima", a partir de unidades bem definidas que vão sendo distribuídas de acordo com regras geradoras da forma.

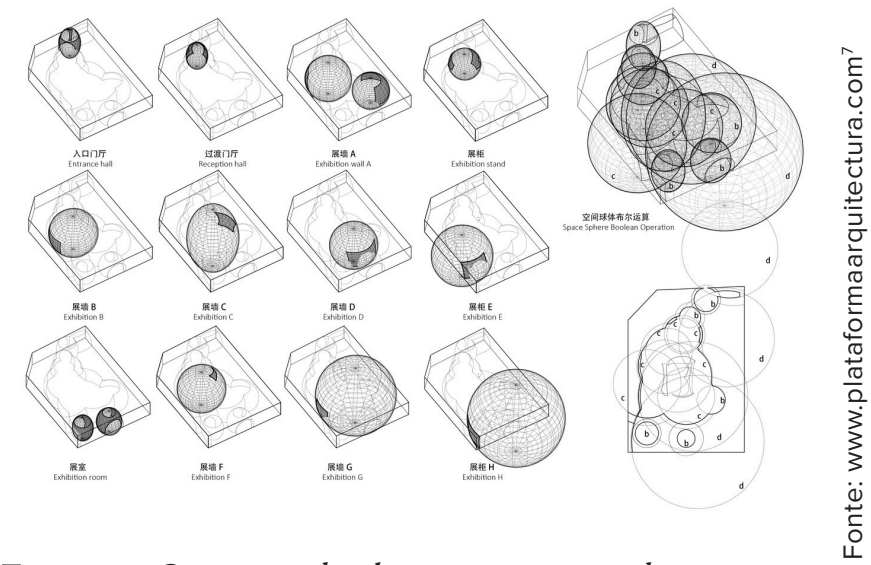

Figura 7: Operaçóes booleanas no espaço de exposiçóes, Museu Jade, de Archi-Union Architects.

A codificação dos desenhos, ou notação, nas definições de Carpo (2011) e Allen (2009), entendida como a "linguagem" estruturada, tende a se concentrar nos desenhos construtivos, mais do que na análise ou na argumentação, pois os primeiros devem funcionar, desde a concepção albertiana da profissão, de modo independente do arquiteto-autor, como descrito por Carpo (2011, p. 46). O convencimento da retórica visual, com seus improvisos e apelos à emoção, cede lugar a imagens que devem ser menos ambíguas - e, portanto, menos abertas a diferentes leituras -, ainda que de interpretação altamente especializada.

Aos aspectos de rigor, escala e codificação acima tratados, poder-se-ia elencar uma extensa variedade de 
outros aspectos gráfico-projetuais que serão eventualmente expressos de modo particular ou específico para cada um dos "momentos": clareza, legibilidade, detalhe, dimensão, proporção, entre outros.

Os desenhos exemplares apresentados foram selecionados para provocar e estimular no leitor a compreensão do valor dessas qualidades; certamente, descobri-las é um desafio, mas são estes aspectos que quando bem resolvidos e bem aplicados darão vida e graça a qualquer desenho.

\section{Conclusão}

Representações são instrumentos extremamente complexos que envolvem uma natureza intuitiva e uma codificação cultural que se combinam e se abrem a uma compreensão. A tentativa de entender as características de uma obra arquitetônica, através de "meros" traços propostos por outrem, é um ato voluntário, "procurar compreender", mas a efetivação da comunicação é incontrolável ou indomável. Ao longo do tempo, inúmeras tentativas foram propostas, absorvidas e registradas. As edificaçóes e as cidades são a prova contundente e inquestionável dos ensaios e esforços humanos.

Identificamos aqui, em consonância com diversos autores, que a representação em arquitetura é, na verdade, plural. Dentro dessa variedade, é possível reconhecer algumas semelhanças e identificar certos tipos de desenho que, embora diferentes quanto às diferentes intençóes do desenho no projeto de arquitetura - análise, argumentação e construção - são etapas de um mesmo processo de criação arquitetônica, sem uma ordem necessária ou gradação de resolução entre eles. Outros sim, salienta-se que devem sofrer alteraçóes profundas, em breve futuro, mesmo que se mantenham mais ou menos fieis aos rituais destacados neste trabalho. Também não se pode associar a cada um escalas exclusivas, ainda que seja possível identificar situaçóes usuais, o que pode contribuir para um olhar inicial sobre eles, mas isso não deve limitar as possibilidades de invenção.

Cada um deles, no entanto, exerce uma função de comunicação específica, seja interna, pública ou especializada (no sentido da construção). Compartilham notações, recursos simbólicos e técnicos, e muitas vezes são simplesmente deslocados de sua situação original para servir a outro propósito de comunicação.

Os recursos de parametrização da realidade aumentada e da realidade virtual trazem novos contornos ao ato projetual e parecem ser um caminho alternativo para variadas experimentaçóes de variadas escalas, dimensôes, programas, entre outras, embora, hoje possam ser associadas principalmente a empreendimentos de grande porte. A realidade imersiva deverá possibilitar empirismo com novas e destacadas consequências e contribuiçóes aos campos cognitivos e emotivos. Como um exercício especulativo, podemos considerar que a abertura da representação em arquitetura para outros campos disciplinares deve ensejar interseccionalidades associadas a percepçóes de múltiplas sensibilidades, que permitirão criar novas perspectivas conceptivas e narrativas a partir de virtualidades informacionais da representação. 


\section{Notas de fim:}

1. Disponível em: https://www.archdaily.com/873477/ the-construction-details-of-elementals-incremental-housing/593b108fe58ece83c5000135-the-construction-details-of-elementals-incremental-housing-monterrey-plans-c-elemental. Acesso em 25/3/2018.

2. Disponível em: https://kaiserscience.wordpress.com/ da-vinci-invention-illustrations/. Acesso em 22/03/ 2018.

3. Disponível em: http://chrisdent.co.uk/portfolio. Acesso em $23 / 03 / 2018$.

4. Disponível em: https://www.archdaily.com/796178/ 42-sketches-drawings-and-diagrams-of-desks-and-architecture-workspaces. Acesso em20/03/2018.

5. Disponível em http:/www.watg.com/london-national-park-city-green-block/. Acesso em23/03/2018.

6. Disponível em https://www.archdaily.com/592660/ nest-we-grow-college-of-environmental-design-uc-berkeley-kengo-kuma-and-associates $/ 54 \mathrm{c} 9 \mathrm{~b} 0 \mathrm{cfe} 58 \mathrm{ece}-$ 457a000216-portada_nest-we-grow_048-jpg. Acesso em23/03/2018.

7. Disponível em: https://www.plataformaarquitectura. cl/cl/867357/museo-jade-archi-union-architects. Acesso em 25/3/2018.

\section{Referências Bibliográficas:}

ALLEN, Stan. Practice - Architecture, Technique and Representation: Revised and Expanded Edition. 2 edition. London ; New York: Routledge, 2009.

ARCHER, Leonard Bruce. The Structure of Design Processes. Thesis, Royal College of Art, 1968. Disponível em: <http://researchonline.rca.ac.uk/2949/>. Acesso em: 11 dez. 2018.

BARKI, José. O risco e a invenção: um estudo sobre as notações gráficas de concepção no projeto. Tese (Doutorado em Urbanismo), UFRJ, 2003.

BARKI, José; MIYAMOTO, James; AZEVEDO, Mauricio Conde. Introdução ao Estudo da Forma Arquitetônica: Caderno Didático da Disciplina Concepção da Forma Arquitetônica I, 2008. Disponível em: <http://www.fau.ufrj.br/ wp-content/uploads/2018/03/FAR112-Apresenta $\% \mathrm{C} 3 \% \mathrm{~A} 7 \% \mathrm{C} 3 \% \mathrm{~A} 3 \mathrm{o}-\mathrm{v} 2 . \mathrm{pdf}>$ Acesso em $16 \mathrm{de}$ março de 2018.

BISELLI, Mario. Arquitetura e ciência. Teoria e prática do projeto arquitetônico. Arquitextos, v. 12, n. 134.00, 2011. (Vitruvius). Disponível em: <http://www.vitruvius.com.br/revistas/read/arquitextos/12.134/3974>.

BLAIR, J. Anthony. The Rhetoric of Visual Arguments. In: HILL, Charles A.; HELMERS, Marguerite (Orgs.). Defining Visual Rhetorics. New Jersey: Taylor \& Francis, 2008, p. 41-62.

BROADBENT, Geoffrey. Design in Architecture: Architecture and the Human Sciences. 1. ed. Londres: John Wiley \& Sons, 1973.

CARPO, Mario. The Alphabet and the Algorithm. 1. ed. Cambridge, Mass.; London: The MIT Press, 2011.

CONAN, Michel. Concevoir un projet d'architecture. Paris: L'Harmattan, 1990.

HERBERT, Daniel M. Architectural Study Drawings. 1 ed. New York: Wiley, 1993.

HILL, Charles A.; HELMERS, Marguerite (Orgs.). Introduction. In: Defining Visual Rhetorics. New Jersey: Taylor \& Francis, 2008, p. 1-23. LASEAU, Paul. Graphic Thinking for Architects and Designers. 3. ed. New York: Wiley, 2000. 
JONES, John Chris. Design Methods. 2 edition. New York, NY: Wiley, 1992.

LASEAU, Paul. Graphic Thinking for Architects and Designers. 3. ed. New York: Wiley, 2000.

PICON, Antoine. A arquitetura e o virtual: Rumo a uma nova materialidade. In: SYKES, A. Krista (Org.). O campo ampliado da arquitetura: Antologia teórica (1993-2009). São Paulo: CosacNaify, 2013, p. 205-220.

PROST, Robert. Conception architecturale: Une investigation méthodologique. Paris: L'Harmattan, 1992.

ROWE, Peter G. Design Thinking. 7. ed. Cambridge, Massachusetts: The MIT Press, 1998.

SAINZ, Jorge. El dibujo de arquitectura: teoría e bistoria de unlenguaje gráfico. Barcelona: Reverté, 2005.

SIMITCH, Andrea e WARKE, Val. The Language of Architecture: 26 Principles Every Architect Should Know. Beverly, Mass: Rockport Publishers, 2014.

WANG, David; GROAT, Linda. Architectural Research Methods. New York: John Wiley \& Sons, 2002.

ZEISEL, John. Inquiry by design: Tools for environment-behavior research. Monterey, Calif: Brooks/Cole Pub. Co, 1981. 